\title{
Artificial Frozen Soil Bending Test and Bending Property
}

\author{
Liu Tao ${ }^{1,2, *}$, Huang $\mathrm{Zhi}^{1}$, Zheng Zhigang ${ }^{1}$, Hong Shaoyou ${ }^{1}$, Li $\mathrm{Jia}^{3}$,Li Youzhi ${ }^{3}$, and Huang Hong ${ }^{1}$ \\ ${ }^{1}$ Shenzhen Yuetong Construction Engineering Co., Ltd, 518019 Ltd. Shenzhen, China \\ ${ }^{2}$ Shenzhen Tagen Engineering Technology Co., Ltd, 518034 Shenzhen, China \\ ${ }^{3}$ Shenzhen Tagen $<$ Group $>$ Co., Ltd, 518034 Shenzhen, China
}

\begin{abstract}
Artificial freezing ground method has been widely used in tunnels, metro and other projects, in the connecting passage in metro, the artificial frozen soil wall, which is formed by artificial freezing method, is often used as temporary support. The artificial frozen soil wall is in the joint action of pressure and bending moment, for it takes the upper pressure and lateral earth pressure at same time, so there may be tensile stress in the profile, which may cause brittle failure. At present, some scholars have carried out researches on the tensile strength with different test methods, but they are insufficiency and have a certain difference in stress state between the specimen and the actual support structure. A bending test instrument was designed and manufacture, which satisfies the code's requirements, and reduces the error caused by poor contact between the specimen and loading device. Bending test on artificially frozen soils was launched using this instrument, and the test on influence law of moisture content and freezing temperature on artificially frozen soils' strength was also launched. The conclusions can provide a reference for design and construction.
\end{abstract}

\section{Introduction}

In 1955, the artificial freezing method construction technology was first applied to the construction of the Kaixi Linxi ventilating shaft excavation construction project. At present, it has been widely used in tunnel and subway soil reinforcement and so on. The physical properties of artificial frozen soil formed by the artificial freezing method directly affect the safety of engineering. Therefore, design and construction personnel should accurately grasp the nature of artificial frozen soil. China has carried out preliminary tests on artificial frozen soil since the 1970s. At present, more mature frozen soil test theories have been formed. For example, the coal industry has formed a relatively mature industry standard for the physical and mechanical properties of artificial frozen soi ${ }^{[1]}$. The standardization of the test method is of great significance for engineering and perfecting the theory of frozen soil, and relevant test methods and standards of artificial frozen soil in urban construction still need to be thoroughly researched and unified.

In engineering design and construction, like brittle materials such as rock and concrete, the tensile strength of frozen soil is a very important mechanical indicator. In urban subway projects, artificial frozen soil walls formed by the artificial freezing method are often used underground. The temporary supporting curtain of the communication channel bears the effect of upper pressure and lateral earth pressure. In this case, the frozen soil is under the combined action of bending and bending. In addition, some parts of the material section are under compressive stress and some are under tensile stress. It is necessary to carry out experimental research on the bending strength of artificial frozen soil. The selection of test methods and test equipment is a prerequisite for obtaining the correct bending strength index of artificial frozen soil. Therefore, this paper first studied the relevant test methods and test equipment. Then this equipment was used for artificial frozen soil tests, and verifying the rationality of the test equipment through the failure mode. At the same time, the bending strength of artificial frozen soil under different influence factors was studied, and reasonable parameters for engineering design can be provided.

\section{Test technology for bending strength of artificial frozen soil}

\subsection{Analysis of the actual stress state and test method of artificial frozen soil wall}

The stress state of the artificial frozen soil wall formed by the artificial freezing method of the subway connection channel is shown in Fig. 1. The frozen soil wall is under the joint action of bending, or the lateral bending effect, and the section may have a tensile stress zone. For this kind of stress state, it is easy to cause unpredictable brittle damage and cause engineering accidents.

At present, domestic and foreign scholars has carried out many tensile strength tests on artificial frozen soils. The engineering properties of artificial frozen soils under complex stress conditions are analyzed by tensile

\footnotetext{
*Corresponding author: 315778102@qq.com
} 
strength. The tensile strength test methods are: uniaxial tensile test method, split test method, three-point loading method.

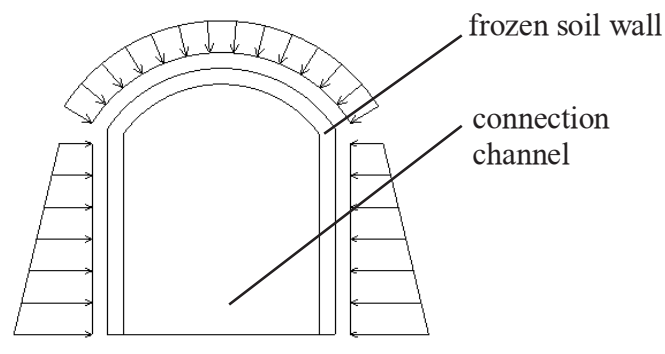

Fig.1 Stress diagram of artificial frozen soil wall in the connecting passage in metro

Zhu Yuanlin and D.L.Carbee ${ }^{[2]}$, Peng Wanwei ${ }^{[3]}$ all studied the tensile strength of frozen soil by uniaxial tensile test method. The ideal direct tensile test requires uniform tensile stress in the axial direction of the test piece, and the fixtures that fix the two ends of the test piece are difficult to obtain, and the effects of microcracks and other manufacturing defects cannot be eliminated. Large error.

Ma Qinyong ${ }^{[4]}$ and Zhao Jingfeng ${ }^{[5]}$ refer to the method for determining the tensile strength of rocks, and use the split method and the Brazilian split test to determine the tensile strength of frozen soil, respectively. This method applies linearity along the diameter of the cylindrical sample, the load causes tensile stress failure in the radial direction of the sample, and the tensile strength is analyzed by elastic theory. The splitting method has the advantages of simple sample preparation and test methods. However, the test tensile strength formula is an elastic mechanics solution from twodimensional problems, and the actual situation cannot meet the plane stress or plane stress conditions required by the formula, which cannot truly reflect the tensile strength of rocks ${ }^{[6]}$.

Based on the problems of these above methods, this paper adopts two-point loading bending strength test method for research. The two-point loading bending (bending and tensile) strength test is an important test for the strength of materials. In this test method, the failure surface of both the bending and tensile states when the specimen is broken. Therefore, the bending strength of the material is a comprehensive reflection of its bending and tensile properties. Research shows that the bending strength and tensile strength of materials are closely related, and the two-point loading test method is easy to control the failure surface between the two loading points, which can reduce the dispersion of small test results is widely used in brittle materials such as rock and concrete. The artificial frozen soil code of the coal industry also specifies the method of bending test.

Using a bending test to determine its bending (that is, bending tensile) strength compared to the uniaxial tensile method and the splitting method to determine its tensile strength more in line with the material's actual stress.

\subsection{Design and development of anti-buckling equipment for artificial frozen soil}

With reference to the requirements of the bending strength test of the physical and mechanical properties of artificial frozen soil in the coal industry ${ }^{[1]}$, the test specimen was a rectangular parallelepiped soil sample with a size of $50 \mathrm{~mm} \times 50 \mathrm{~mm} \times 200 \mathrm{~mm}$. Two loading points were designed, which were located at the two third-grade sub-points of the sample span. The loading condition is shown in Fig. 2.

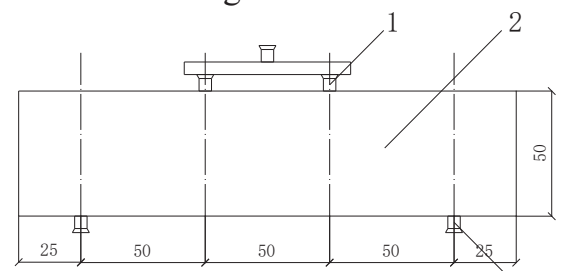

3

1- Pressure point, 2- Sample, 3- Bearing point a). Loading device schematic

Fig.2 Schematic diagram of the sample

The stress condition of the test piece can be simplified as that the simply supported beam is subjected to concentrated load. The part between the two loading points of the sample receives a uniform bending moment, so that the failure surface of the specimen can be controlled to occur between the two loading points. According to the formula for calculating the strength of a simply supported beam under concentrated load, when the frozen soil specimen yields or is brittlely fractured, the following formula can be used to calculate the beam's bending strength.

$$
f_{f}=\frac{P l}{b h^{2}}
$$

In the formula, $f_{f}$ is the bending strength of the test piece; $l$ is the distance between the supports; $b$ and $h$ are the width and height of the cross section of the test piece, respectively.

This test device was made on the basis of a uniaxial compression test device for artificial frozen soil. The incubator (minimum temperature $-40{ }^{\circ} \mathrm{C}$ ) can ensure the temperature of the test piece is constant during the test. The control system can set the loading method to be controlled by force or displacement. The acquisition system can automatically collect the variables such as the load and displacement applied during the test.

With experience continuously accumulating during the test, the equipment has been continuously improved. The loading device and the support device are important parts of the equipment to complete the bending test. The support device and the loading device are made of steel, and the surface hardness is much greater than the hardness of the test piece, so it is made into an arcshaped end face with a diameter of $10 \mathrm{~mm}$ to avoid excessive indentation on the specimen due to stress concentration or even support device penetrating into the specimen during the loading process, and the two loading points of the loading device and one load point of the support device are designed to rotate around the width of the test piece to ensure that the specimen is in 
good contact with the loading device and avoid the error caused by the contact between the specimen and the loading device in the test. The support device and loading device used are shown in Fig. 3. The support device is fixed to the base of the press machine, and the loading device is hinged to the pressure shaft of the press machine. The bending test device is placed in a temperature-controlled test box, and the temperature fluctuation around the sample during the test is controlled to not exceed $\pm 0.1^{\circ} \mathrm{C}$.
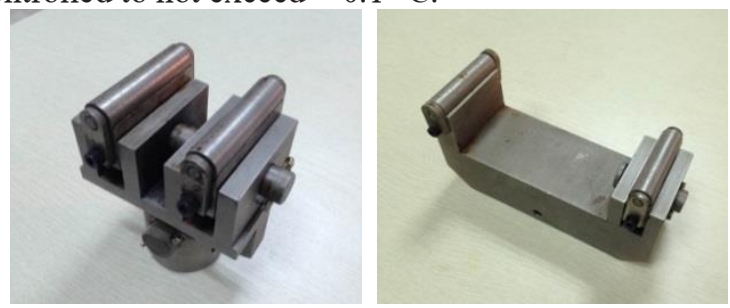

Fig.3 Loading and support device

\subsection{Verification of bending test equipment for artificial frozen soil}

Frozen soil bending strength test was carried out using the developed artificial frozen soil bending test equipment, and the load was continuously and evenly loaded at a speed of $60 \mathrm{~N} / \mathrm{s}$. As shown in Fig. 4, the data acquisition system recorded the load applied during the test and the deflection of the test piece, and the bending strength of the test piece can be obtained by formula (1).
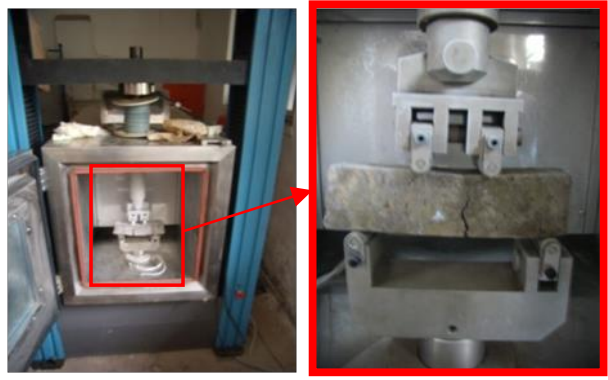

Fig.4 Bending test on artificial frozen soils

In the initial stage of test loading, the bending strength increased with the deflection, and the relationship between the two was close to linear. When the stress exceeded the ultimate strength, the test piece suddenly broke and could hardly bear the load. When the test piece is broken, the crack suddenly appeared on the side of tensile stress and sharply developed towards the compressive stress side until the specimen breaks. The load on the specimen decreased sharply, and there was no gradual decay process of the load, which shown typical brittle failure characteristics. Observing the morphology of the specimens after the destruction, it is found that there was an obvious main crack that almost runs through the entire cross section.

\section{Bending test of artificial frozen soil with different soil quality}

The freezing temperature and moisture content of artificial frozen soil are two important parameters, which have an important influence on the bending strength of artificial frozen soil. This paper used a designed bending test equipment to study the influence of freezing temperature and moisture content on bending strength.

\subsection{Experimental scheme}

The test studied the bending properties of three kinds of artificial frozen soils of silty clay, clay and silt. The test was divided into two groups: The first group of samples were made of undisturbed soil of different soil types, and were subjected to fracture resistance tests at $-10^{\circ} \mathrm{C}$, $15^{\circ} \mathrm{C}$, and $-20^{\circ} \mathrm{C}$, respectively. The second group of samples were made from the remolded soil of the corresponding soil, and remolded soil samples with different moisture contents $(15 \%, 20 \%, 25 \%, 30 \%, 35 \%$, $40 \%$ ) were prepared respectively for fracture resistance test at $-10^{\circ} \mathrm{C}$

\subsection{Test results and analysis}

\subsubsection{Effect of temperature on bending strength}

The bending strength-deflection curves of undisturbed soil samples of different soil qualities at different test temperatures are shown in Fig. 5.

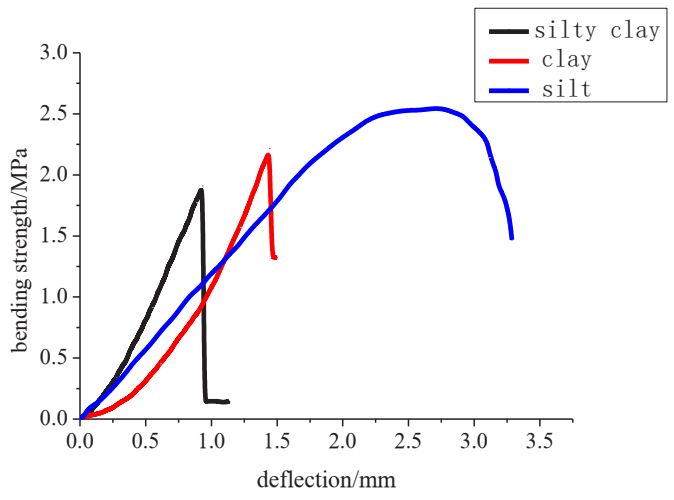

a). Test temperature in $-10{ }^{\circ} \mathrm{C}$

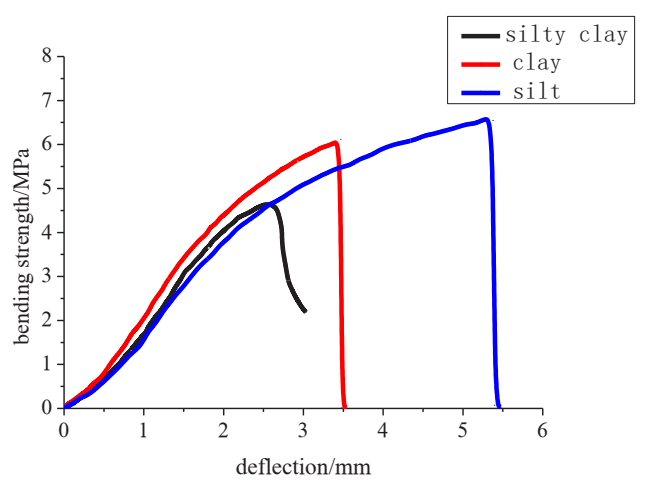

b). Test temperature in $-15{ }^{\circ} \mathrm{C}$ 


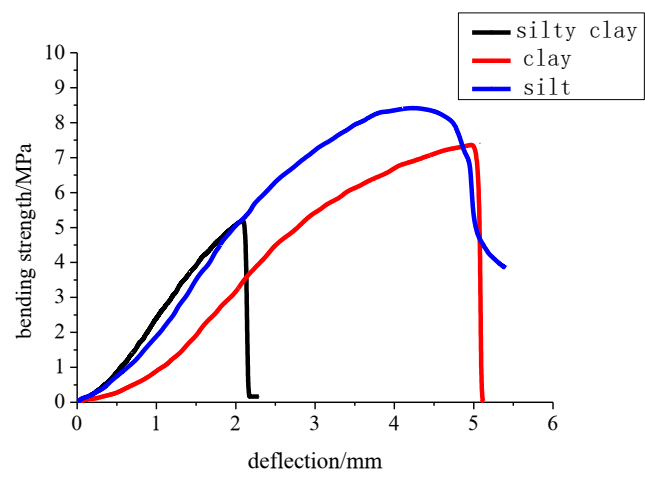

c). Test temperature in $-20{ }^{\circ} \mathrm{C}$

Fig.5 Bending strength-deflection relationship curve

From the bending strength-deflection curves of different soil samples, it can be seen that the artificial frozen soil samples of the three soil types all show typical brittle failure. In the initial stage of loading, the stress increases rapidly with the strain, the curve is close to a straight line. In addition, the growth rates of different soils were significantly different when the freezing temperature was higher (such as $-10^{\circ} \mathrm{C}$ ), while the growth rates of different soils were less different when the freezing temperature was lower (such as $20^{\circ} \mathrm{C}$ ).

The bending strength of undisturbed soil samples of different soil quality at different temperatures is shown in Table 1. It can be seen that the bending strength of the specimen increases with decreasing temperature, and the effect of temperature on the bending strength is reduced. It is very obvious that the bending strength of silt, clay and silty clay at $-20^{\circ} \mathrm{C}$ is $3.35,3.34$ and 2.79 times stronger than that at $-10^{\circ} \mathrm{C}$, respectively.

Table 1 Bending strength at different temperatures

\begin{tabular}{|c|c|c|c|}
\hline \multirow{2}{*}{ temperature $/{ }^{\circ} \mathrm{C}$} & \multicolumn{3}{|c|}{ bending strength/MPa } \\
\cline { 2 - 4 } & silt & clay & silty clay \\
\hline-10 & 2.54 & 2.21 & 1.90 \\
\hline-15 & 6.51 & 6.05 & 4.63 \\
\hline-20 & 8.51 & 7.39 & 5.30 \\
\hline
\end{tabular}

\subsubsection{Effect of moisture content on bending strength}

To test the effect of moisture content on the bending properties of artificial frozen soil, silt, clay, and silty clay remolded soils with moisture content of $15 \%, 20 \%, 25 \%$, $30 \%, 35 \%$, and $40 \%$ were prepared. The samples were subjected to a bending test at $-10^{\circ} \mathrm{C}$ to obtain the relationship curves between the bending strength and the moisture content of artificial frozen soil of different soil types, as shown in Fig. 6.

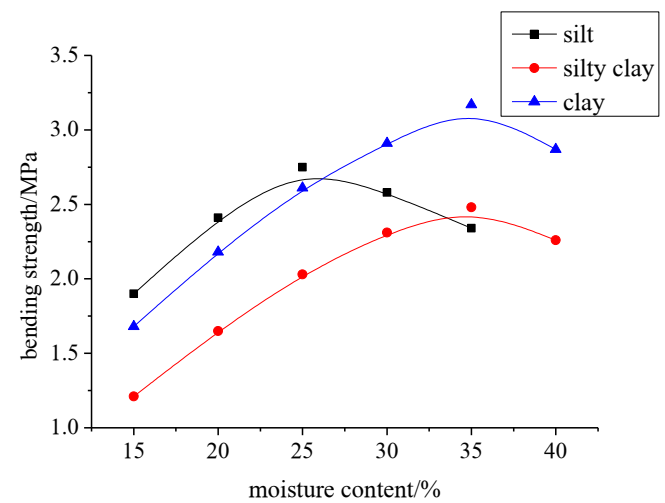

Fig.6 the bending strength-moisture content relationship of different soils texture

From Fig. 6, the influence of moisture content on the bending strength of artificial frozen soil can be obtained: the bending strength of artificial frozen soil of different soil qualities increased first and then decreased as the moisture content increases, and there was always an optimal moisture content that makes the flexural strength highest; However, the best moisture content corresponding to the maximum bending strength of artificial frozen soil specimens with different soil properties were different. The silt was about $25 \%$, and the silty clay and clay were closer, which were about $35 \%$.

\section{Conclusion}

Based on the uniaxial compression test equipment for frozen soil, this paper designs and manufactures the artificial frozen soil bending test equipment, which can meet the requirements of the bending test and reduce errors caused by poor contact between the test specimen and the loading device. Using this equipment, the effects of freezing temperature and moisture content on bending strength were studied, and the following conclusions can be obtained:

(1) The bending strength of artificial frozen soil samples of different soil quality at different temperatures increases with temperature decreasing, and the effect of temperature on bending strength is very obvious;

(2) The bending strength of artificial frozen soils of different soil qualities increases first and then decreases with the increase of moisture content, and there is always an optimal moisture content that makes the flexural strength highest. However, the best moisture content corresponding to the maximum bending strength of artificial frozen soil specimens with different soil properties are different. The silt is about $25 \%$, and the silty clay and clay are closer, which are about $35 \%$.

\section{References}

1. State Administration of Work Safety, MT/T593.1-8, Artificial frozen soil physics mechanics performance test, (2011) 
2. Zhu Yuanlin, David L.Carbee. Tensile Strength of Frozen Silt, Journal of Glaciology and Geocryology, 8 (1986)

3. Peng Wan-wei. Tensile strength of frozen loess varying with strain rate and temperature, Chinese Journal of Geotechnical Engineering, 20 (1998)

4. Ma Qin-yong. Tensile Strength, Uniaxial Compressive Strength Test on Artificially Frozen Soils, Rock and Soil Mechanics, 17 (1996)

5. Zhao Jing-feng. An experimental study on the relationship between tensile strength and temperature and water ratio of frozen soil, Geology and Exploration, 47 (2001)

6. Yu Yong. Questioning the validity of the Brazilian test for determining tensile strength of rocks, Chinese Journal of Rock Mechanics and Engineering, 24 (2005) 